\title{
UN TORO DE BRONCE ORIENTALIZANTE EN MENORCA
}

\author{
AN ORIENTALIZING BRONZE BULL IN MENORCA
}

RAIMON GRAELLS I FABREGAT

Römisch-Germanisches Zentralmuseum, Mainz

JAVIER JIMÉNEZ ÁVILA

Junta de Extremadura

JOAN C. DE NICOLÁS MASCARÓ

Recercat, Institut Menorqui d'Estudis

\section{INTRODUCCIÓN}

Dar a conocer hallazgos sueltos, muchas veces descontextualizados, tiene una doble motivación. Por un lado, registrar y valorar documentos relevantes para la investigación histórica y arqueológica y, por otro, sirve para ejemplificar y actualizar problemáticas de las que participa la pieza objeto del trabajo. A tal efecto, el ejemplo debe tener unas características tipológicas o informativas particulares que supongan anomalías en cuanto a aspectos de distribución espacial, uso, cronología o morfología. Todos estos aspectos se aúnan en la pequeña figura de bronce de la presente noticia.

Las páginas que siguen analizan una figura de toro de tipo orientalizante hispano ${ }^{1}$ recuperado en el interior de la isla de Menorca. La falta de contexto obliga a contemplar varias hipótesis para comprender este hallazgo fuera de su área de distribución esperada.

De este modo se ha organizado el trabajo en base a una secuencia lógica de descripción de la pieza, seguido por una contextualización del hallazgo para, al final, proponer las distintas hipótesis interpretativas para comprender su presencia en Menorca.

\section{DESCRIPCIÓN DE LA PIEZA}

Depósito: Museo Diocesano de Menorca. Sección de Arqueología ( $\sin \mathrm{n}^{\circ}$ de inventario). Depósito particular (Figs. 1 y 2).

Dimensiones: 94 x 47 x $50 \mathrm{~mm}$.

Peso: 125 gr.

Material y técnicas: bronce fundido en hueco a la cera perdida, posteriormente retocado e inciso.

\footnotetext{
1. Aunque siempre se han denominado bronces tartésicos, parece más probable considerarlos como producciones fenicias o, si se prefiere, orientalizantes de la Península Ibérica, denominación que aquí utilizaremos.
}
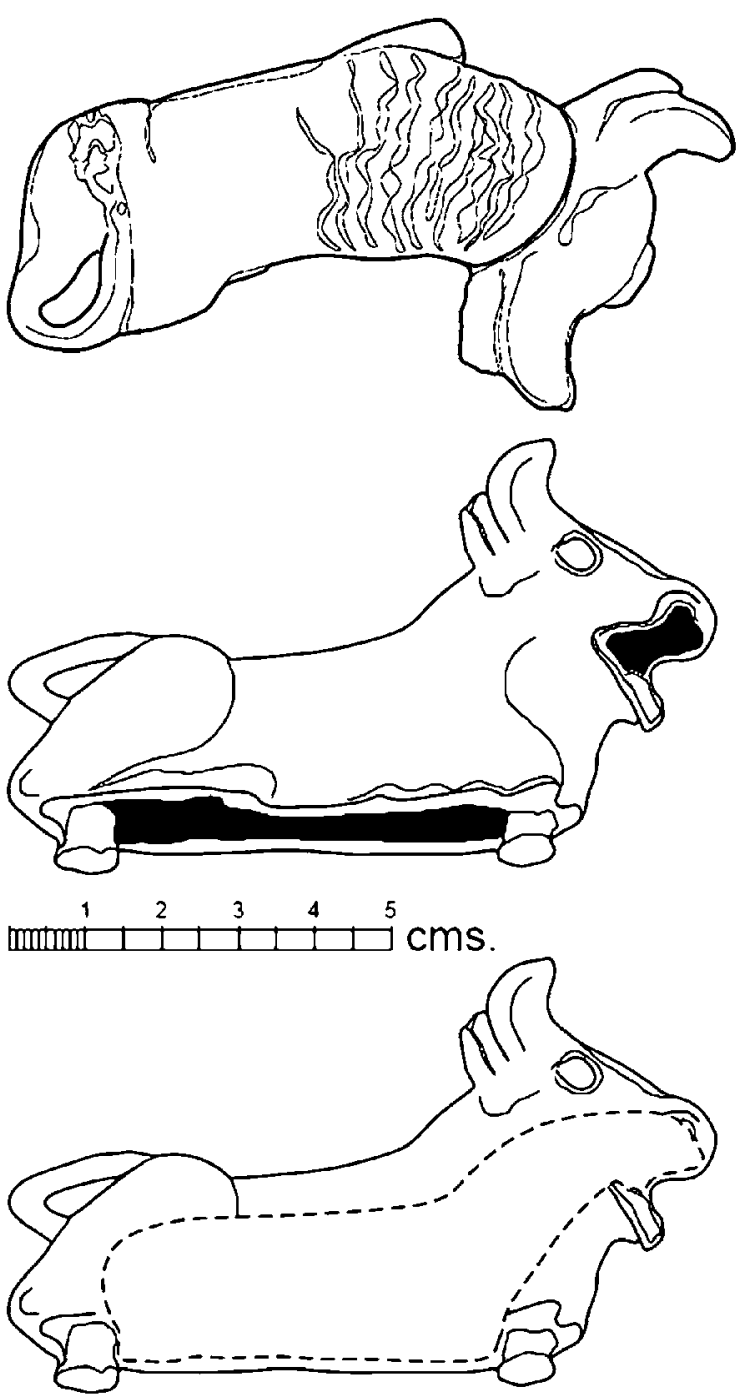

Figura 1: Dibujo del toro de Menorca (Autor: J. C. de Nicolás).

Conservación: buena, pese a la existencia de algunos pequeños focos de cloruros, hoy estabilizados.

Descripción: figura de toro en posición de descanso, echado en el suelo, con las extremidades flexionadas 

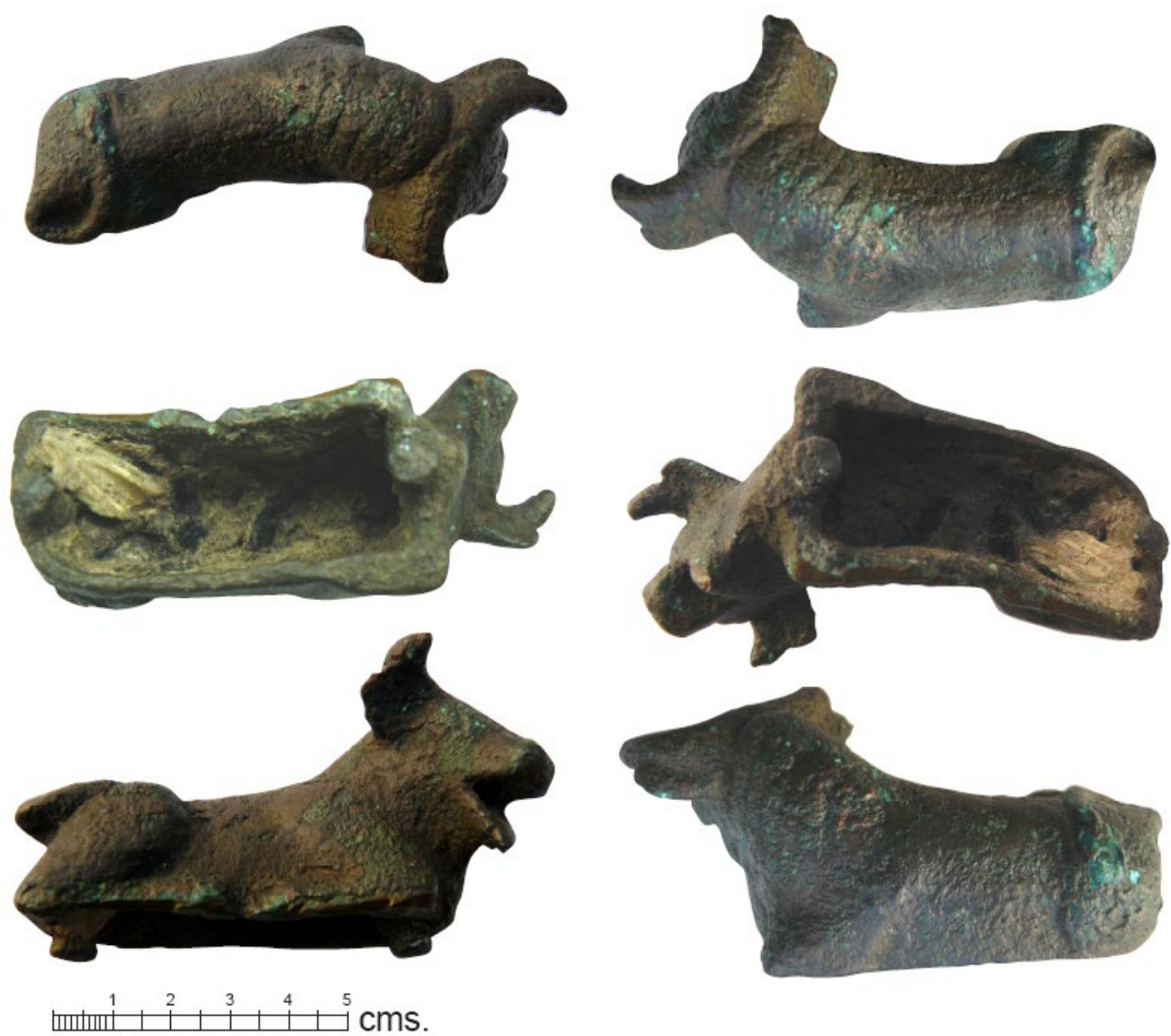

Figura 2: Fotografías del toro de Menorca (Autor: J. C. de Nicolás).

y cortadas a nivel de las articulaciones medias como la parte inferior del abdomen del animal. La cola se aprecia entera, girada y dispuesta sobre la grupa, con su extremo bien marcado, aunque algo deteriorado por cloruros estabilizados. El cuello y cabeza del animal están marcadamente girados hacia la derecha con los cuernos ligeramente en alto y la boca abierta apuntando parte de la lengua hacia el exterior. Se aprecian los ojos, almendrados, ligeramente marcados. Las orejas se presentan prácticamente unidas a los cuernos formando un mismo cuerpo y los pliegues cutáneos, representados convencionalmente, caen a ambos lados del cuello perfectamente ordenados.

Fundido a la cera perdida con cuerpo refractario interno. Éste dejó un amplio hueco en el vientre del animal que tiene salida hacia el exterior a través de la boca abierta. Tras la fusión se efectuaron recortes formando una irregular superficie basal que da estabilidad a la pieza y cuyas paredes tienen un grosor de 2 a 3 milímetros. Su función es adaptar la pieza a un soporte o tapadera, asegurando su fijación a la misma con dos clavos o espigones remachados, fundidos conjuntamente con el resto de la pieza, en los extremos distales de la mencionada superficie basal.

En el hueco interno del toro se localizan restos de sedimentos terrosos de color grisáceo y unos pequeños fragmentos de madera carbonizada así como un fragmento óseo calcinado.

\section{CONTEXTO, ANTECEDENTES Y CIRCUNS- TANCIAS DEL HALLAZGO}

Rafal des Frares o d'El Toro, en el término municipal de Es Mercadal, es una de las fincas más cercanas a la mayor elevación de la isla, Monte Toro (258 m s.n.m.). El topónimo es conocido en la literatura arqueológica balear y particularmente en la menorquina, ya que antes de 1890 fueron halladas varias figuras de bronce sobre las que, a partir de la información publicada hasta ahora, sólo puede proponerse que procedan de esa finca, aunque sin ubicación precisa ni contexto alguno (Hernández Sanz, 1908, 95).

Hasta 1983 se habían identificado en el entorno de Monte Toro -en menorquín 'El Toro'- dos grupos de yacimientos o entidades de interés arqueológico, uno en la finca de Lanzell en la vertiente oriental y nororiental de la montaña (dos posibles asentamientos fortificados y un viejo camino empedrado) y un gran asentamiento en las laderas del Sur y del Oeste, cuya superficie supera la hectárea en las fincas de Sant Nicolau d'El Toro, Sant Carles d'El Toro y Rafal des Frares, denominado genéricamente como el yacimiento de Rafal des Frares o d'El Toro ${ }^{2}$. Mascaró menciona

2. Mascaró, 1980; 1983, 36 y 42. La fichas que se recogen en los catálogos de J. Mascaró Pasarius son: 
que se ven ruinas de numerosas edificaciones de planta rectangular y absidal, con molinos de mano y fragmentos de cerámicas indígenas, púnicas y romanas. En este contexto menciona los hallazgos de una sirena, un bailarín (antes denominado «droméus» o corredor) y una figura femenina arrodillada, todos en bronce.

Pocos años después, antes de 1990, las revisiones del catálogo de patrimonio histórico arqueológico efectuadas para el Ayuntamiento de Es Mercadal y para la Administración Autonómica consiguieron afinar la ubicación de los yacimientos, manteniendo los tres elementos del primer grupo y dividiendo el segundo grupo de asentamientos en cinco zonas arqueológicas diferenciadas: dos en la finca de Sant Nicolau d'El Toro, uno en la de Sant Carles d'El Toro y otros dos en Rafal des Frares, si bien no se obtuvo más información sobre el hallazgo de los primeros bronces ${ }^{3}$.

La información obtenida sobre actividades irregulares y la presencia de nuevos bronces, que se conservan en el Museo Diocesano de Ciutadella (entre ellos el toro orientalizante que nos ocupa) y en una colección particular, sugiere que proceden del yacimiento RFR-01. En este, en reciente visita efectuada con la arqueóloga del Servicio de Patrimonio del Consell Insular de Menorca (Dña. J. Gual), se observan escasas evidencias de cultura material prerromana mientras que, paralelamente, presenta una intensa acumulación de restos de época medieval. En cualquier caso, actualmente apenas se observan restos de estructuras arquitectónicas.

El yacimiento prerromano y medieval RFR-01, que es el que ahora nos interesa, apenas es reconocible

- Lanzell (LAN-01), $\mathrm{N}^{\mathrm{o}}$ de inventario oficial: 1970, posible camino antiguo;

- Lanzell (LAN-02) (Es Caragol) $\mathrm{N}^{0}$ de inventario oficial: 1970 (a), yacimiento en altura, posible fortificación;

- Lanzell (LAN-03) (Es Coll Verd), $\mathrm{N}^{\circ}$ de inventario oficial: 1970 (b), posible talaiot;

- Rafal des Frares o d'El Toro, $\mathrm{N}^{\circ}$ inventario oficial 1977, restos de un poblado que se extiende de norte a sur a lo largo de la cota 203 de El Toro en su ladera occidental, sobre un ribazo rocoso que arranca desde las inmediaciones d'Es Pas d'es Bou y terminaba en tierras de Sant Carles del Toro, ocupando también terrenos de Sant Nicolau y del Rafal des Frares o d'El Toro.

3. A partir de dos informes inéditos de J.C. de Nicolás [Catàleg de protecció del patrimoni històric (arqueològic, etnologic $i$ arquitectònic) del terme municipal d'es Mercadal. (Ajuntament d'es Mercadal, 1988-1990) y Carta arqueologica dels termes municipals d'es Mercadal i de Migjorn Gran. (Direcció General de Cultura, Educació i Esports. Govern Balear, 1989. Servei de Patrimoni (Consell Insular de Menorca)] se indidividualizan cinco yacimientos: Rafal des Frares (RFR01) (Es Forn de calç de baix); Rafal des Frares. (RFR-02) (Tanca de sa Senyora); Sant Carles d'El Toro (SCT-01); Sant Nicolau d'El Toro (SNI-01) (Es Pas d'El Toro, o Peus d'El Toro); Sant Nicolau d'El Toro (SNI-02). También se localizan los yacimientos o referencias de Lanzell que ya apuntaba J. Mascaró: Lanzell (LAN-01); Lanzell (LAN-02). Es Caragol; Lanzell (LAN-03). debido a la intensa explotación agropecuaria de algunas parcelas y a la presencia de monte bajo. Se localiza en una de las laderas meridionales, al Sur-Oeste de El Toro y a 475 metros en línea recta de la cima. Sus coordenadas son: $39^{\circ} 58^{\prime} 55^{\prime \prime} \mathrm{N} / 04^{\circ} 06^{\prime} 35^{\prime \prime} \mathrm{E}$ y su elevación es de 184 m s.n.m.

Entre los materiales atribuidos a esta procedencia destaca una sirena ${ }^{4}$; una figura mutilada que ha sido definida como Venus arrodillada o, incluso Afrodita saliendo del baño, datada en el siglo IV a.C. y conservada en el Museo de Menorca ${ }^{5}$; y una figura masculina, interpretada como representación de 'bailarín', de filiación etrusco-campana de finales del siglo VI y de primeros del V a.C. ${ }^{6}$ Menos conocidos y atribuidos a la misma área donde se propone el hallazgo del toro, proceden otros objetos o fragmentos de objetos de bronce: un pie izquierdo de estatuilla; una doble hacha con mango (posible complemento de estatuilla); una garra sobre placa circular, posible pie de lámpara o recipiente metálico; una cabeza con gorro cónico, probablemente de una figurilla de guerrero baleárico. Todos ellos de la misma colección particular actualmente depositada en el Museo Diocesano de Menorca, en Ciutadella ${ }^{7}$.

El toro de Rafal des Frares o d'El Toro, como otras piezas del mismo yacimiento fue hallado, al parecer, con detector de metales entre 1965 y 1977, efectuándose su depósito en el Museo Diocesano de Menorca, Sección de Arqueología, en Ciutadella, hacia 1987.

\section{PARALELOS}

Esta nueva figura tauromorfa del Museo Diocesano de Menorca en Ciutadella viene a sumarse a una lista de figuraciones similares que aparecen asociadas al momento orientalizante en la Península Ibérica. Todas ellas presentan una serie de características comunes muy estereotipadas: la posición del animal, echado y con la cabeza erguida mirando en posición transversal al cuerpo; la boca abierta con la lengua cayendo sobre el belfo inferior (rasgo compartido con otras especies

4. Las circunstancias de su incorporación a los fondos del Museo Diocesano de Menorca antes de 1890 en: Mascaró, 1983, 42 y 44; cronología y encuadre cultural con bibliografía anterior en: Orfila, 1983, 134-135.

5. Orfila, 1983, 136-137, con bibliografía anterior. Esta pieza, y la siguiente, formaron parte de la colección Ramis antes de incorporarse a la de Antonio Vives Escudero.

6. La misma procedencia tendría un aplique de crátera monumental de tipo laconio, según notas manuscritas de Vives Escudero. Este aplique fue publicado en el marco del estudio del fondeadero de Cales Coves (Belén y FernándezMiranda, 1979, 156, lám. XIII) . Para un estudio de la pieza vid. Kukahn, 1969, 440-441; Orfila, 1983, 105-108; Graells, 2006-2007, 299, fig. 4, nota 299.

7. Los tres primeros publicados junto a otros objetos de bronce en Mascaró, 1983, 9.92; los fragmentos de guerrero en: Orfila, 1983, 108-109 y 122-124. 

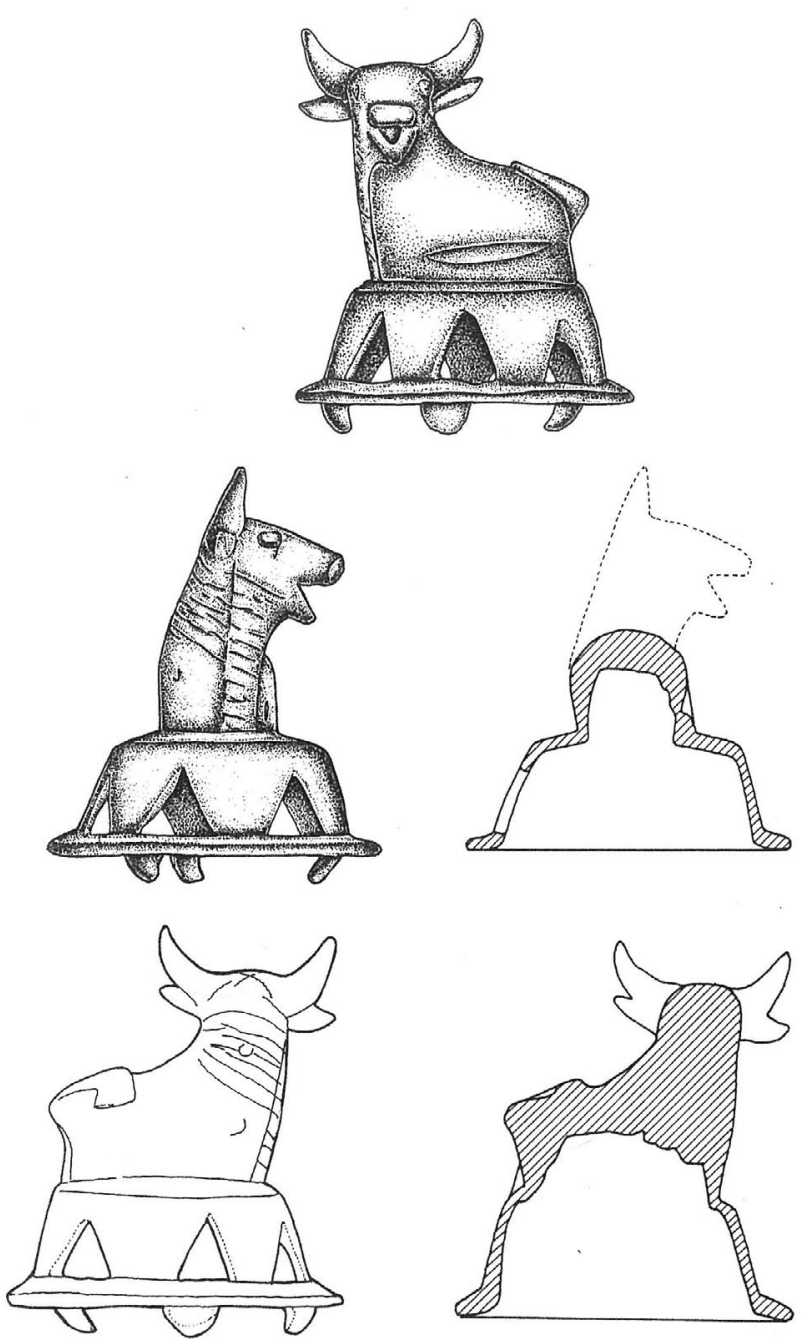

Figura 3: Dibujo del timiaterio de Safara (Moura, Portugal) (Autor: J. Jiménez Ávila).

animales representadas en esta época); el trabajo de los pliegues cutáneos, muy marcados en la zona de la cerviz y la cola vuelta sobre el lomo, formando una típica curvatura y ensanchada o apaletada en el extremo. A veces se complementan con decoraciones incisas, incluso en sitios que no coinciden con rasgos anatómicos.

Desde el punto de vista funcional se interpretan como asas o agarraderos que rematarían las tapaderas de timiaterios o quemaperfumes de bronce, uno de los más típicos productos salidos de las oficinas de los toreutas fenicios occidentales (Jiménez Ávila, 2002).

El primero de estos toros se atribuye a Safara (Moura, Portugal) (Figs. 3 y 4), aunque hay un debate sobre el argumento ${ }^{8}$. Presenta las características descritas, muy esquemáticamente tratadas, y la peculiaridad de estar fundido conjuntamente con la tapa del

8. Recientemente Soares, 2012.

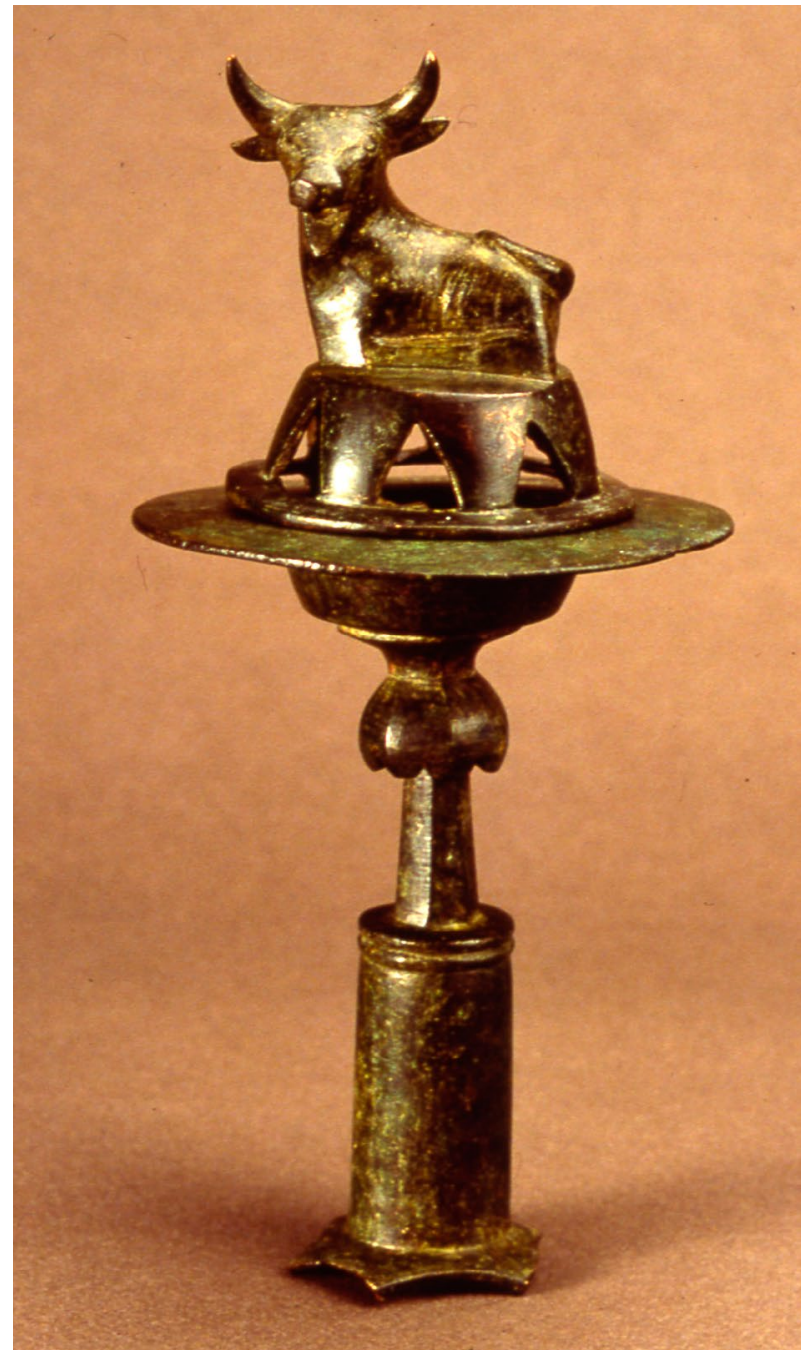

Figura 4: Fotografía del timiaterio de Safara (Moura, Portugal) (Museu Nacional de Arquelología, Lisboa).

timiaterio, lo que despeja cualquier duda sobre su funcionalidad. Junto a la tapa se encontró la cazoleta unida al fuste del quemaperfumes, que hoy se conservan en el Museo de Belem de Lisboa (Vasconcellos, 1924; Almagro-Gorbea, 1977; Jiménez Ávila, 2002).

Una esculturilla en similar posición apareció en la rica tumba de Los Higuerones de Cástulo (Jaén) (Fig. 5), desprovista de la cabeza y asociada a los restos de un timiaterio del que, muy precariamente, también se conservaba la tapa (Blázquez, 1975; Jiménez Ávila, 2002). Sobre la reconstrucción de este timiaterio ha habido varias propuestas, al plantearse inicialmente la posibilidad de que fuera una esfinge de bronce encontrada con el ajuar la que rematara el quemaperfumes (Blázquez, 1975). Sin embargo, la revisión detenida del depósito obliga a cuestionar esta opción, ya que la esfinge se acopla a una placa de bronce trabajada con zapa por la parte inferior, formando un tipo de utensilio que, según reciente propuesta, podría tener la funcionalidad de rallador (Galán, 2010). Consecuentemente, debe de ser la esculturilla tauromorfa la 

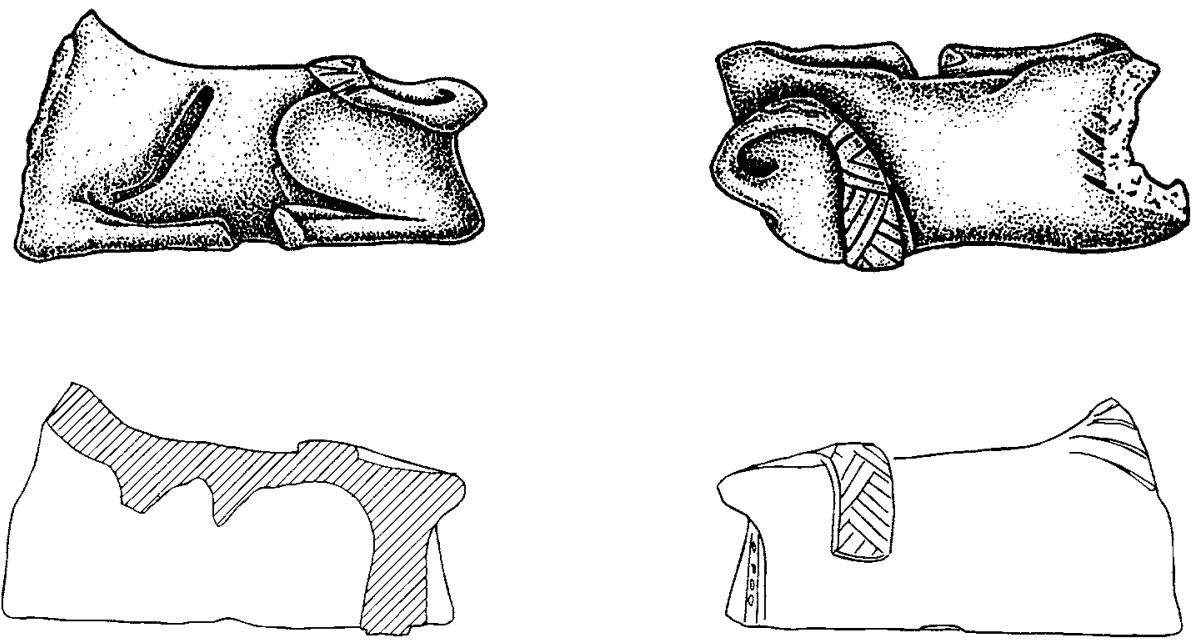

Figura 5: Dibujo del toro de la tumba de la necrópolis de Los Higuerones en Cástulo (Prov. Jaén) (Autor: J. Jiménez Ávila).
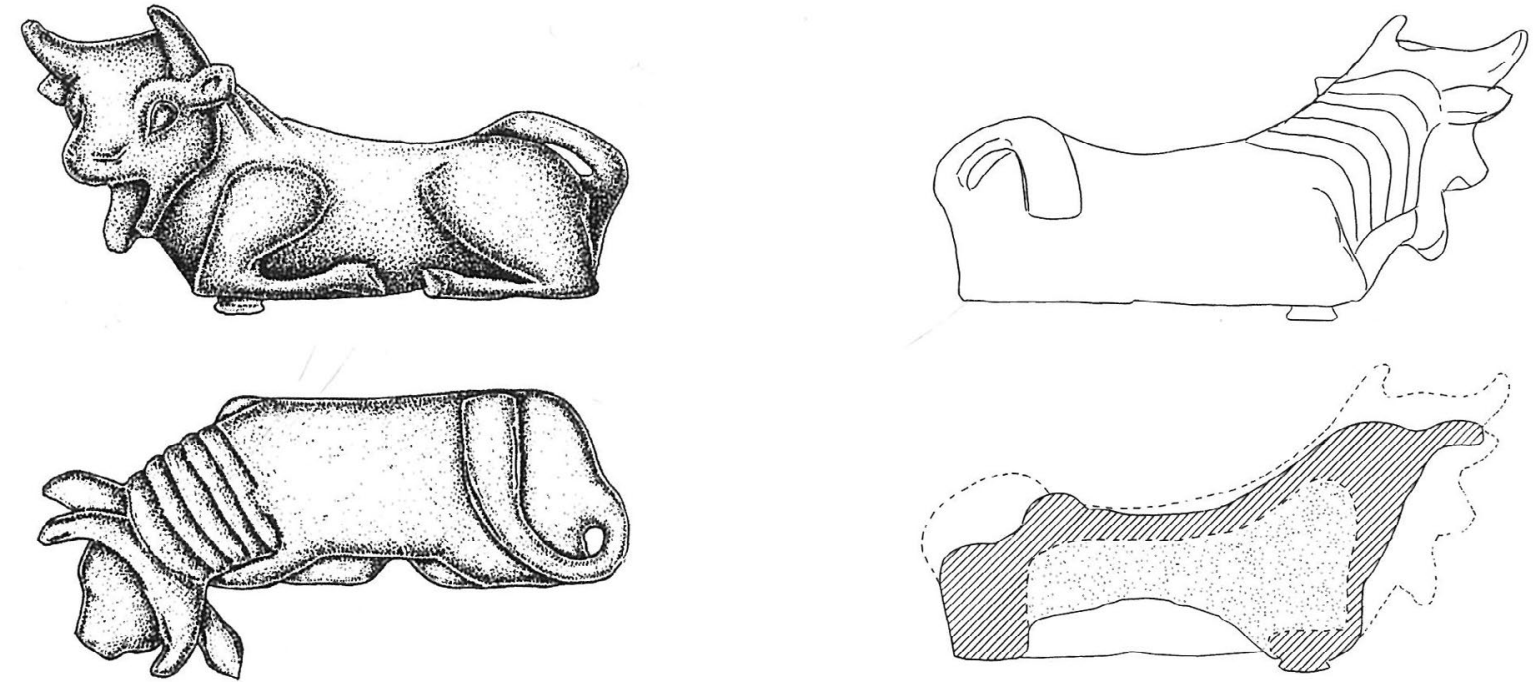

Figura 6: Dibujo del toro de Alcalá del Río (Prov. Sevilla) (Autor: J. Jiménez Ávila).

que rematara la tapa perforada de este quemaperfumes castulonense, tal y como sucede en el ejemplar de Safara.

Siguiendo estos antecedentes, se han interpretado también como asas zoomorfas de timiaterios las esculturillas tauriformes de Alcalá del Río (Sevilla) (Fig. 6) y Mourão (Portugal) (Fig. 7). La primera de ellas, conservada en el MAN, es la que más se parece al ejemplar del museo menorquín, y presenta la peculiaridad de estar rellena en su interior hueco con un vertido de plomo de difícil explicación (Olmos y Fernández Miranda, 1987; Jiménez Ávila, 2002). En la parte delantera, como el ejemplar que aquí presentamos, conserva el botón que la uniría a la tapadera. Por su parte, el toro de Mourão es el que más se aleja del resto del conjunto, por su mayor decoración y superior calidad. Además aparece mirando a la derecha, rasgo también distintivo. Estas peculiaridades han hecho que se haya llegado a publicar como una posible importación oriental (Gomes, 1992) si bien, a la vista del conjunto, lo más probable es que, como las demás, se trate de una producción peninsular algo más cuidada, y que tengamos que considerar que hubiera distintos talleres o distintas gamas productivas en la organización de los toreutas fenicios de la península Ibérica (Jiménez Ávila, 2002).

Junto a estas figuritas de toros, de cara a su verificación como asas de tapaderas de timiaterios, es necesario citar también la aparición de esculturillas representando otras especies animales - ciervos en particular - trabajadas con el mismo fin. Es el caso de los ejemplares de La Codosera (Badajoz) y La Lagartera (Cáceres). El primero, como el de Safara, aparece fundido conjuntamente con la tapa calada, mientras 

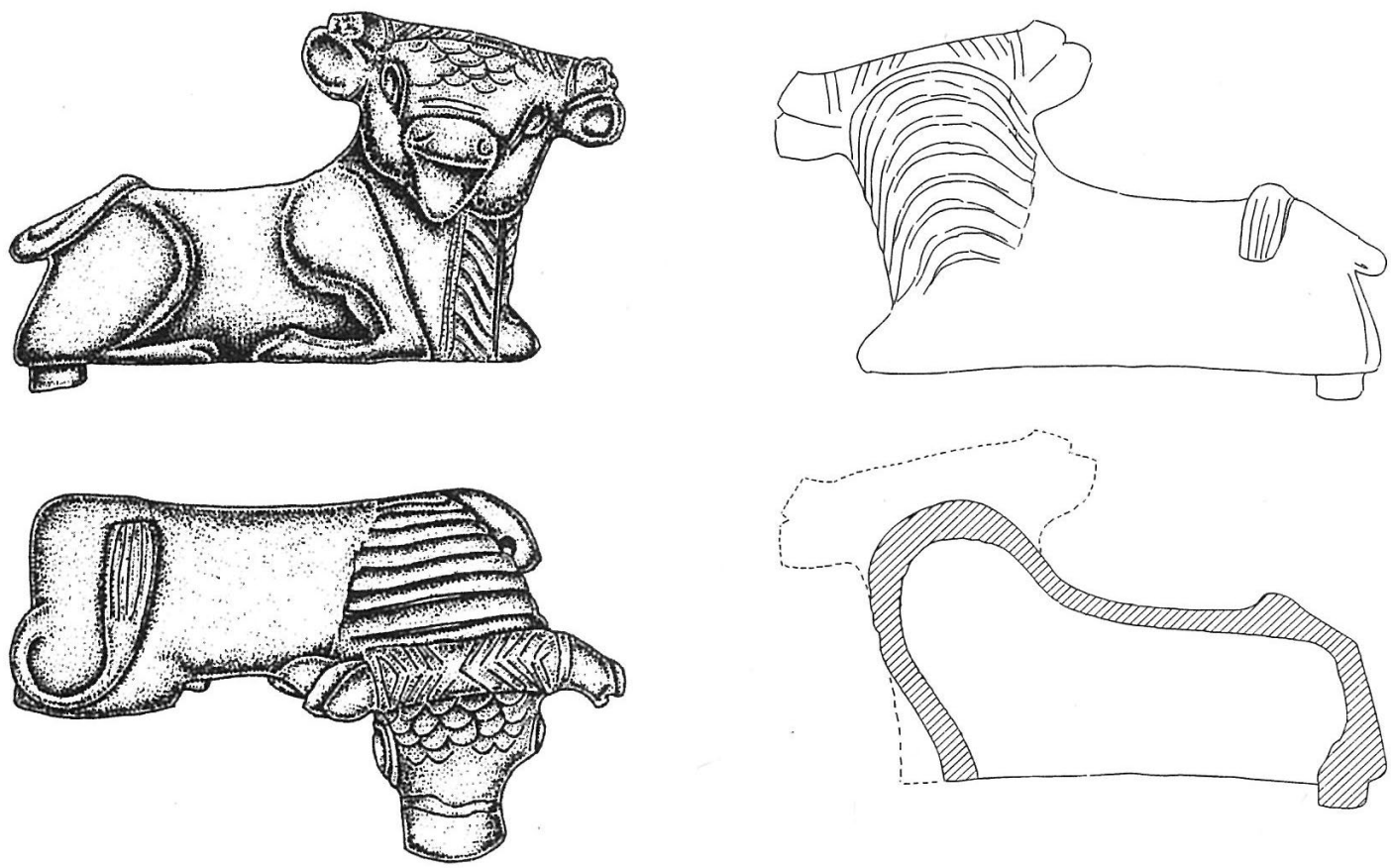

Figura 7: Dibujo del toro de Mourão (Portugal) (Autor: J. Jiménez Ávila).

que el segundo, más próximo al nuestro desde el punto de vista técnico, aún conserva la trabazón entre las dos piezas (Jiménez Ávila, 2002). Este último ejemplar comparte, además, algunos de los rasgos típicos de la iconografía orientalizante, como el ya mencionado gesto de exhibir la lengua cayendo sobre el labio inferior.

Al igual que sucede con los toros, también se conservan algunas esculturillas de ciervos aislados que podrían interpretarse como asas historiadas de tapas de timiaterios.

Estas figuraciones de animales en similar posición encuentran buenos referentes en el oriente del Mediterráneo desde la Edad de Bronce (Catling, 1964, lám. 44d) lo que, para el caso de los hallazgos peninsulares, justifica su consideración como productos fenicios. Sin embargo, existen elementos suficientes como para, dentro de esta tradición semita, establecer que se trata de una producción peninsular de carácter local. Así, sobre todo, su abundancia en el Extremo Occidente, que viene avalada por el nuevo ejemplar del Museo Diocesano de Menorca. Su aplicación a las tapas de timiaterios parece exclusiva del Mediterráneo occidental, pero se conocen otros casos (muy raros) donde se adoptan soluciones distintas, caso del timiaterio de Santa Giusta (Cerdeña), donde la tapa se remata con una cabeza de toro y no en un animal de cuerpo entero (Bernardini y Botto, 2010, fig. 44.2). Finalmente, la frecuencia de determinadas especies, como los cérvidos, que se repite en otros elementos de la broncística peninsular y que contrasta con la relativa rareza de este animal en la iconografía de Oriente.

Dentro de este panorama y, salvando la circunstancia de su hallazgo insular, el toro del Museo de
Menorca queda así perfectamente integrado dentro de esta producción fenicia del extremo occidental del Mediterráneo.

\section{CIRCULACIÓN DE BRONCES ENTRE EL SUR DE LA PENÍNSULA IBÉRICA Y MENOR- CA: ¿UN NUEVO PARADIGMA ENTRE LOS SS. VII-VI A.C.?}

La presencia de materiales fenicios en las Baleares ha sido abundantemente considerada, pero cabe decir que su concentración se sitúa en Ibiza, siendo escasos en Mallorca y Menorca. Esta presencia fenicia se inserta en una red de intercambios entre el sur de la Península Ibérica y las grandes islas mediterráneas aunque cabe decir que la presencia de materiales orientalizantes peninsulares es, hasta hoy, inexistente entre los materiales de este circuito.

La aparición de esta esculturilla tauriforme en Rafal del Toro, desprovista de cualquier dato sobre su contexto, o sus circunstancias de hallazgo plantea una serie de problemas y de posibilidades explicativas que justificarían su presencia en la isla ${ }^{9}$. De este modo, si

9. Lamentablemente, éste fenómeno es habitual entre los objetos protohistóricos baleares. Especialmente claro en el más completo catálogo de las figuras de bronce protohistóricas mallorquinas donde de los 122 objetos estudiados más del 50\% son hallazgos casuales de cuyo contexto no se sabe nada o prácticamente nada, y el resto proceden en gran parte de excavaciones arqueológicas antiguas que solo se han publicado de forma resumida con las dudas y los problemas de precisión y fiabilidad cronológica que comporta (Gual, 1993, 40). 


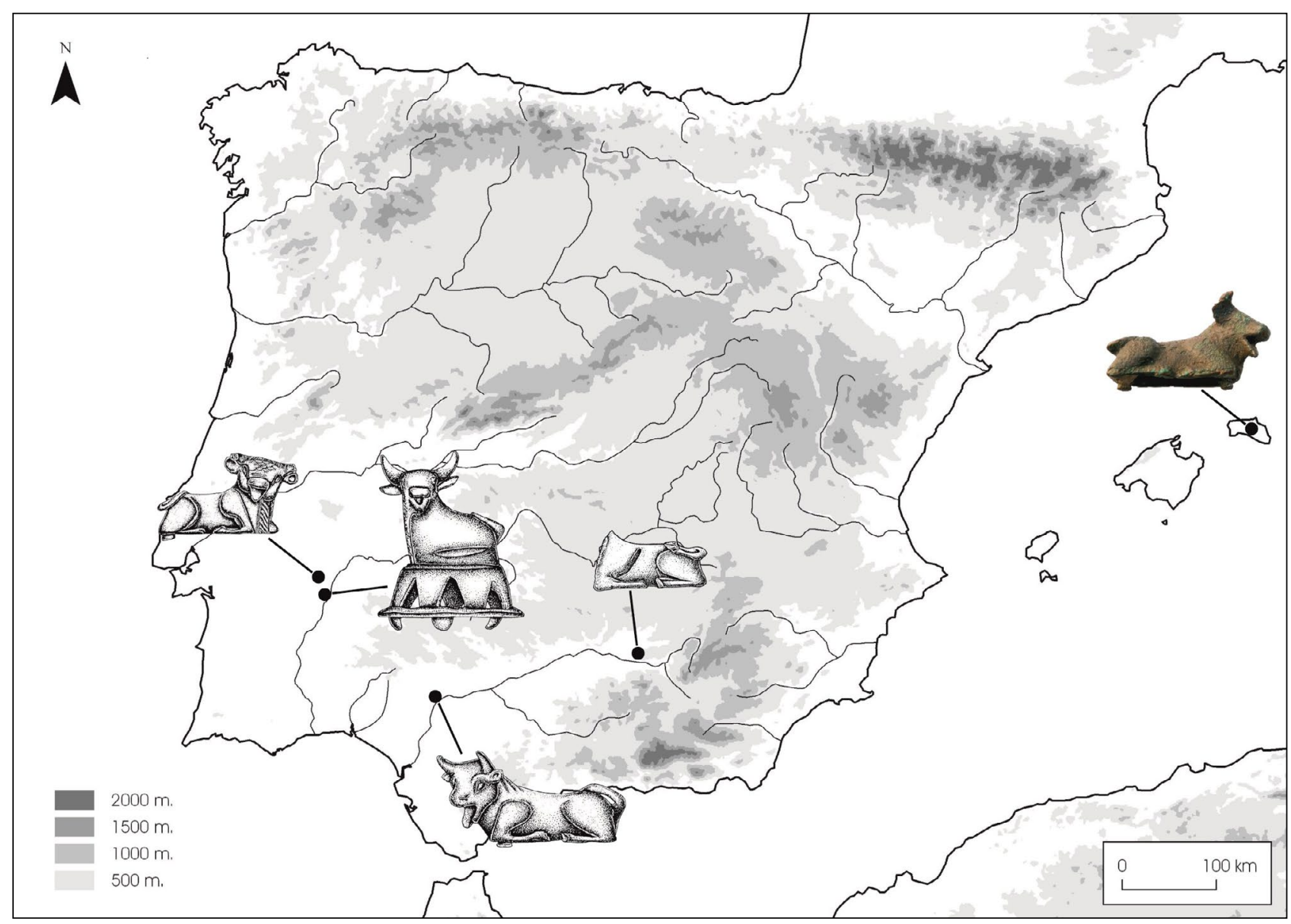

Figura 8: Mapa de distribución de los timiaterios de bronce con figuras de toro orientalizante (Autor: R. Graells).

aceptamos el hallazgo de la pieza en Menorca (Fig. 8), falta comprender si se trata de un caso excepcional de intercambio o comercio de bienes de prestigio entre el sur de la Península Ibérica y la isla o si se trata de una circulación del fragmento per se que podría ser resultado de unos circuitos de aprovechamiento de metal para refundición o de circulación de metal para prácticas votivas complejas desde el sur de la península hacia Menorca. Aquí se discuten estas opciones.

En primer lugar, debemos considerar la posibilidad de que hubiera llegado a Menorca formando parte de un timiaterio completo y en uso durante la época de utilización de estos elementos rituales, es decir, durante los siglos VII y VI a.C. A favor de esta posibilidad juega la proximidad de la isla de Ibiza, donde han aparecido dos elementos de bronce relacionables con este tipo de producciones: el timiaterio de Sa Barda (Almagro-Gorbea, 1970; Olmos, 1992) y un soporte de tipo chipriota, de más reciente hallazgo, aún inédito. Pero, no obstante, este escenario tropieza con algunas dificultades, como la rareza del hallazgo fuera del entorno peninsular y alejado de contextos de aristocracias orientalizadas. Aún así, y pese a la falta de datos contextualizados, no puede negarse un cierto dinamismo insular en redes de intercambio de larga distancia a partir del final de la Edad del Bronce. Sea como fuere, a partir de la
Primera Edad del Hierro, y especialmente a partir del s. VI a.C., la presencia de materiales paleoibéricos ${ }^{10}$

10. Dos colgantes de tipo carnero con base sogueada de tipo Ba (Graells y Sardà, 2005, 13, fig. 4), con varios tramos de cadenitas rematadas en colgantes esféricos y una decena de colgantes esféricos proceden del hipogeo XIX de Cales Coves (Veny, 1982, 81-95, fig. 48,30; 97-102, fig. 55,4; 342); tres colgantes zoomorfos en forma de paloma, con anilla en el lomo y un pequeño apéndice esférico con anilla de tipo 1 de Rafel, y dos fragmentos de las peculiares cadenitas de pequeños eslabones circulares (sin contexto). Aún así, la relación con el nordeste de la Península Ibérica y con el Golfo de León viene enfatizado por la presencia de un brazalete dentado de tipo launaciense en Cales Coves.

En relación al hallazgo de Cales Coves, N. Rafel (1997, 104) considera su situación geográfica de difícil interpretación en clave de rutas de intercambio mientras que los colgantes de Puig dels Molins parecen ser «el resultado de los bien atestiguados intercambios comerciales entre la isla y la costa catalana». Esto puede relacionarse con la identificación de produccions cerámicas a mano del mundo talayótico junto a otras del Sureste y de la costa catalana en el yacimiento de Sa Caleta (entre el 15 y 20 \%) (Ramón et alii, 2011, 63), lo que evidencia un peso específico de Ibiza en estas redes de intercambio, cosa que parece marginal en relación con Menorca. 
y fenicios ${ }^{11}$ se ha documentado en la isla, aunque no pueden atribuirse a un establecimiento de comunidades fenicias en la propia isla sino a contactos esporádicos. En este marco, el timatierio podría tener cabida (Jiménez Ávila, 2010). Aún así, la propia escasez de bronces fenicios en Baleares y en la propia Ibiza son factores que invitan a la prudencia.

La segunda opción es que la escultura hubiera llegado a la isla, ya desprendida del quemaperfumes y perdida su función como asa, durante los siglos posteriores al uso de estos bienes. Esta hipótesis cuenta con un elemento a su favor: los restos óseos y de carbón que se conservan en la parte interior de la figura y que podrían corresponder a los vestigios de una cremación del tipo de las documentadas en el sur de la Península Ibérica en época orientalizante (Torres, 1999). Aquí se abren varios caminos: que llegara por su valor como masa de bronce, para ser refundida en circuitos de circulación de chatarra; o (más sugerente) que hubiera sido seleccionada como ofrenda, bien por su valor iconográfico (ya que las figuras de toros constituyen una de las constantes más evidentes entre las creencias religiosas de las poblaciones baleáricas durante la Pre- y la Protohistoria). Mientras que el valor como metal tiene una interpretación sencilla, la segunda posibilidad queda enmarcada en una dinámica especialmente rica en ejemplos en Sicilia, donde la presencia de fragmentos de objetos de bronce (mayoritariamente de ornamentación personal femenina) documenta un flujo importante entre el sureste francés y la isla. En esta dinámica, la presencia de fragmentos de otros objetos, figurados incluso, es minoritaria aunque no ausente. No se conoce en el Mediterráneo occidental ningún fenómeno similar, donde la presencia de depósitos u objetos de bronce de tipo launaciense es muy escasa (Graells, 2011a, 2013 y 2014). En cualquier caso, el ejemplo siciliano abre la posibilidad a esta interpretación.

Una tercera opción se desprende de la valoración conjunta de los distintos objetos atribuidos a Rafal del Toro. La mezcla de piezas singulares o figuradas, de distintas filiaciones culturales, artísticas y

11. En la reexcavación del hipogeo XXI de Cales Coves se recuperó un pendiente de plata, que se ha relacionado con producciones argénteas fenicias del suroeste que podría asociarse al intérvalo 830-760 a.C. lo que viene a a reforzar, en opinión de los autores, la presencia de intercambios con los fenicios desde los primeros momentos de la cultura talayótica (Gornés, Gual y Gómez, 2006, fig. 3.4); También la presencia de una lucerna de dos picos con engobe rojo y base convexa no diferenciada del hipogeo LIV de Cales Coves, corresponde a esta serie de objetos fenicios (Veny, 1982, 180-183, fig. 114-115, lám. 39); En cuanto a las cuentas de pasta vítrea con decoración oculada o gallonada, presentes entre otros yacimientos menorquines en la necrópolis de Cales Coves (hipogeos 19, $21,48,54,56,80,86$ y 91), aunque no puede afirmarse que correspondan a piezas coetáneas al toro pues es bien conocida su larga perduración hasta el siglo III a.C. cronológicas, obliga a considerar un marco especial, donde tanto su amplia cronología (entre el arcaísmo y el clasicismo) como su particular concentración topográfica dificultarían comprenderlos como ricos testimonios hallados en distintos yacimientos sincrónicos situados en esa área, o de yacimientos que se suceden en el tiempo, lo que lleva a plantear la hipótesis de vincularlos a un posible espacio de culto usado durante un tiempo dilatado. Así, el toro orientalizante y los ya publicados, encontrarían cierta lógica en un área sacra de advocación indeterminada con ofrendas singulares y con una cronología que iría desde la primera mitad del siglo VI hasta, quizás, mediado el siglo IV a.C. ${ }^{12}$ Pero esta concentración de piezas excepcionales necesita cierta prudencia antes de su automática aceptación, pues ni el toro ni el resto de objetos publicados o mencionados anteriormente como atribuidos a Rafal des Frares han sido registrados de una forma científica ni adecuadamente documentada, como correspondería a todo bien patrimonial merecedor de un tratamiento arqueológico fiable y contrastable. La diversidad de todas esas piezas atribuidas a Rafal des Frares (todas descontextualizadas), no ofrece un marco lógico en el que encajar la presencia del toro orientalizante en la isla ${ }^{13}$. De este modo, considerar la posibilidad de la interferencia de ciertas prácticas de la tradición anticuaria, debe ser tenida en cuenta (Gómez de Soto y Milcent, 2000; Graells, 2011b y 2014) $)^{14}$.

\section{CONCLUSIONES}

La presencia de una pieza tan singular en las Islas Baleares, cualquiera que haya sido el proceso de su llegada a la isla, queda sin poderse analizar en su detalle ante la falta de contexto. Por ello, su publicación implica un dilema: por un lado, dar a conocer el toro dentro de una dinámica antigua (de circulación de objetos de bronce desde el sur de la Península Ibérica, bien como piezas enteras en calidad comercial o como recogida de fragmentos, tal y como se ha documentado en otras

12. En esta idea de santuario se ha manifestado también J.S. Gornés (1997, 59, nota 5), destacando la singularidad topográfica en Es Peus del Toro (Mercadal). En este mismo sentido, no se debe olvidar la confirmación del carácter sagrado de Monte de Toro en épocas más recientes como la Edad Media.

13. Esta misma propuesta ha sido realizada recientemente para otros bronces arcaicos recuperados sin contexto, que formaron parte de colecciones arqueológicas particulares y que no encuentran correspondencia con los contextos arqueológicos del área en la que se supone se hallaron (Bardelli y Graells, 2012).

14. El falseamiento de procedencias con finalidades comerciales o de carácter científico, fueron prácticas habituales que han supuesto graves problemas para el posterior estudio y contextualización de piezas. Para una discusión y bibliografía sobre el argumento vid. Graells, 2011b y 2014. 
áreas del Mediterráneo central) (Verger y Pernet (Dir.), 2013; Baitinger, ep.) y por otro, rechazar un documento de importancia para la comprensión de la protohistoria del Mediterráneo occidental por la falta de su contexto. En ambos casos la decisión es complicada y por ello aquí hemos querido valorar la pieza como un nuevo ejemplar del catálogo de bronces orientalizantes peninsulares $y$, en paralelo, hemos realizado una aproximación amplia hacia sus posibles interpretaciones como hallazgo balear que sólo nuevos descubrimientos contextualizados verificarán o refutarán.

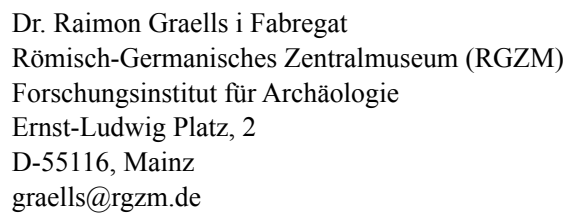

Javier Jiménez Ávila

Consejería de Educación y Cultura

Junta de Extremadura

Avda. de Huelva, 2

06001 Badajoz

jjimavila@hotmail.com

Joan C. de Nicolás Mascaró

Institut Menorquí d'Estudis

Camí des Castell, 28

07702 Maó (Menorca)

\section{BIBLIOGRAFÍA}

ALMAGRO-GORBEA, M., 1977: El Bronce Final y el Periodo Orientalizante en Extremadura. Bibliotheca Praehistorica Hispana XIV, Madrid.

ALMAGRO GORBEA, M.J., 1970: «Un quemaperfumes en bronce del Museo Arqueológico de Ibiza», Trabajos de Prehistoria, 27, 191-200.

BAITINGER, H., ep.: Die Metallfunde aus Selinunt - Der Fundstoff aus den Grabungen des Deutschen Archäologischen Instituts auf der Agora, Sonderschriften des DAI, Roma, en prensa.

BARDELLI, G. y GRAELLS, R., 2012: «Wein, Weib und Gesang. A propósito de tres apliques de bronce arcaicos entre la Península Ibérica y Baleares», Archivo Español de Arqueología, 85, 23-42.

BELÉN, M. y FERNÁNDEZ-MIRANDA, M., 1979: El fondeadero de Cales Coves (Alayor, Menorca), EAE 101, Madrid.

BERNARDINI, P. y BOTTO, M., 2010: «I bronzi «fenici» della Penisola Italiana e della Sardegna», Rivista di Studi Fenici, XXXVIII.1, 17-118.

BLÁZQUEZ, J.M., 1975: Tartessos y los orígenes de la Colonización fenicia en la Península Ibérica, Salamanca, $2^{a}$ edición.

CATLING, H. W., 1964: Cypriot Bronze-Work in the Micenaean World, Oxford.

GALÁN, E., 2010: «Tapadera o rallador», en Cádiz y Huelva. Puertos fenicios del Atlántico (Catálogo de la Exposición), 284-285, Sevilla.
GOMES, M.V., 1992: «Proto-História do Sul de Portugal», en Próto-História de Portugal, 99-185, Lisboa.

GÓMEZ DE SOTO, J. y MILCENT, P.Y., 2000: «De la Méditerranée à l'Atlantique: échanges et affinités culturelles entre le nord-ouest (Armorique, Centre-Ouest, Limousin) et le sud-ouest de la France (principalment Languedoc occidental) de la fin du Xe au Ve s. avant J.C», en Th. JANIN (Dir.), Mailhac et le premier âge $d u$ Fer en Europe occidentale, Hommages à Odette et Jean Taffanel, 351-371, Lattes.

GORNÉS, J.S., 1997: «Reflexiones en torno al simbolismo tauromorfo en la Prehistoria de Menorca», Meloussa, 4, 57-64.

GORNÉS, J.S., GUAL, J.N. y GÓMEZ, J.L., 2006: «Avanç dels contexts arqueològics i de la cronologia absoluta de l'hipogeu XXI de Cales Coves», Mayurqa, 31, 165-181.

GRAELLS, R., 2006-2007: «Los prótomos de caldero de tipo oriental en la Península Ibérica: aproximación al problema y valoración», en R. GRAELLS (Coord.), El valor social $i$ comercial de la vaixella metàl.lica al Mediterrani centre-occidental durant la protohistòria, Revista d'Arqueologia de Ponent, 16-17, 292-299.

GRAELLS, R., 2011a: «El conjunto de bronces picenos del depósito «de Tarragona» en el Museu Episcopal de Vic (Barcelona)», Jahrbuch des RGZM, 58, 243-278.

GRAELLS, R. 2011b: Dactyliothecae Cataloniae: El col-leccionisme de glíptica a Catalunya abans de 1900. Espai / Temps, 58. Edicions de la Universitat de Lleida, Lleida.

GRAELLS, R., 2013: «Le dépôt de bronzes d'el Turó de la Font de la Canya (Avinyonet del Penedès, Tarragone)», en S. VERGER y L. PERNET (Dirs.), Une Odyssée gauloise. Parures de femmes à l'origine des premiers échanges entre la Grèce et la Gaule, Coll. Archéologie de Montpellier Agglomération 4, 215-216, Arles.

GRAELLS, R., 2014: «Problemas de cultura material: Las fibulas itálicas de la primera Edad del Hierro en el Golfo de León Occidental», Madrider Mitteilungen, 55, 212-315.

GRAELLS, R. y SARDÀ, S., 2005: «Entre carneros, palomas y ciervos: la asimilación de estimulos mediterráneos a través de la Toréutica. El ejemplo del noreste de la Península ibérica durante el s. VI aC», Rivista di Studi Liguri, LXXI, 5-28.

GUAL, J., 1993: Figures de bronze a la protohistòria de Mallorca, Maó.

HERNÁNDEZ SANZ, F., 1908: Compendio de geografía e historia de la isla de Menorca, Mahón.

JIMÉNEZ ÁVILA, J., 2002: La Toréutica Orientalizante en la Península Ibérica, Bibliotheca Archaeologica Hispana 16 , Madrid.

JIMÉNEZ ÁVILA, J., 2010: «Bronces fenicios: ¿los bronces de los fenicios?», en XXIV Jornadas de Arqueología fenicio-púnica, Trabajos del Museo Arqueológico de Ibiza y Formentera, 65, 23-46.

KUKAHN, E., 1969: «Una aplicación de una kratera de bronce, griega», en X Congreso Nacional de Arqueología (Mahón, 1967), 440-441, Zaragoza. 
MASCARÓ, J., 1980: Carta arqueológica de Mercadal, Festes d'Es Mercadal, Es Mercadal.

MASCARÓ, J., 1983: «Carta arqueológica de Menorca», en J. MASCARÓ (Coord.), Geografía e Historia de Menorca IV, 2-106, Menorca.

OLMOS, R., 1992: «Broncística fenicia y orientalizante en el Sur Peninsular y en Ibiza. Una aproximación iconográfica y simbólica», en VI Jornadas de Arqueología fenicio-púnica, Trabajos del Museo Arqueológico de Ibiza y Formentera, 27, 41-64.

OLMOS, R, y FERNÁNDEZ MIRANDA, M., 1987: «El timiaterio de Albacete», Archivo Español de Arqueología, 60, 211-219.

ORFILA, M., 1983: «Estatuillas de Bronce antiguas», en J. MASCARÓ (Coord.), Geografía e Historia de Menorca IV, 85-158, Menorca.

RAFEL, N., 1997: «Colgantes de bronce paleoibéricos en el NE de la Península Ibérica. Algunas reflexiones sobre las relaciones mediterráneas», Pyrenae, 28, 99-117.

RAMÓN, J., RAFEL, N., MONTERO, I., SANTOS, M., RENZI, M., HUNT, M.A. y ARMADA X.L., 2011:
«Comercio protohistórico: el registro del Nordeste peninsular y la circulación de mineral de plomo en Ibiza y el Bajo Priorato (Tarragona)», Saguntum (P.L.A.V.), 43, 55-81.

SOARES, R.M.G.M., 2012: O Cabeço Redondo, um edificio da idade do ferro pós-orientalizante na Herdade do Metum (Moura), Tesis de Mestrado, Universidade de Lisboa.

TORRES, M., 1999: Sociedad y Mundo Funerario en Tartessos, Bibliotheca Archaeologica Hispana 3, Madrid.

VASCONCELLOS, J.L. de, 1924: «Figuras de bronze antigas do Museu Etnológico Português», O Arqueólogo Português, XXVI, 29-36.

VENY, C., 1982: La necròpolis protohistòrica de Cales Coves, Menorca, Bibliotheca Praehistorica Hispana XX, Madrid.

VERGER, S. y PERNET, L. (Dirs.), 2013: Une Odyssée gauloise. Parures de femmes à l'origine des premiers échanges entre la Grèce et la Gaule, Coll. Archéologie de Montpellier Agglomération 4, Arles.

Recepción: 24-07-2013

Aceptación: 20-11-2013 